En los primeros estadios del aprendizaje de la traducción de literatura para niños, ciertas ideas preconcebidas como son la permeabilidad al intervencionismo o la sencillez del proceso de traducción, pueden condicionar las decisiones de traducción. Algo similar ocurre también en la práctica de la traducción de literatura para niños cuando esta no va acompañada de una reflexión sobre sus características, condicionantes y restricciones.

En este artículo nos planteamos la necesidad de reflexionar sobre las características de la traducción de literatura para niños y sobre los tópicos que gravitan en torno a ella, antes de enfrentarnos a su traducción. Partiremos para ello de una experiencia docente llevada a cabo con los estudiantes del Grado en Traducción e Interpretación de la Universitat Jaume I de Castellón, en el marco de la asignatura de Traducción especializada español-catalán.

PALABRAS CLAVE: Audiencia, manipulación, enseñanza de la traducción, traducción español-catalán

\title{
Traducir literatura para niños: de la teoría a la práctica
}

Cristina García de Toro Universitat Jaume I

\section{Translating Children's Literature: from theory to practice}

In the first stages of learning to translate children's literature, translation decisions can be conditioned by certain preconceived ideas such as the perceived free hand to manipulate a translation or the simplicity of the translation process. Something similar also occurs in the practice of translating children's literature when it does not coincide with reflection on the characteristics, conditioning factors and restrictions of the translation.

We argue in this paper that there is a need to reflect on the characteristics of translating children's literature, and on the stereotypical notions that surround it, before embarking on the translation itself. The paper is based on an educational experience with Translation and Interpreting Degree students at the Universitat Jaume I of Castellón, as part of the Spanish-Catalan specialised translation course.

KEY WORDS: audience, manipulation, translation teaching, Spanish-Catalan translation. 
Cuando presentamos la traducción de literatura para niños a los estudiantes de traducción, observamos que una serie de ideas, fuertemente interiorizadas, planean en la mente de los futuros traductores. La primera es la de la sencillez del género: los estudiantes parten del supuesto de que la dificultad de la traducción de la literatura para niños será menor que la de la traducción de literatura para adultos, por lo que requerirá un esfuerzo menor. Y la segunda idea tiene que ver con la permeabilidad del género al intervencionismo: bajo la premisa de que los niños aprenden de lo que leen, los estudiantes asumen un papel de didactas de una manera más o menos instintiva y, una vez resguardados bajo el paraguas del didactismo, creen que su función consiste en intervenir y manipular el texto, en la mayoría de ocasiones simplificándolo, para adecuarlo a lo que consideran apropiado a sus capacidades, a su comprensión lectora, a su bagaje cultural, o a lo que las normas sociales aconsejan.

Pero tanto una idea como otra reclaman un espacio de reflexión. Que los textos sean en apariencia sencillos no implica necesariamente que el proceso de traducción se convierta en una operación sencilla. La traducción de literatura para niños es una actividad poliédrica y condicionada, como lo son otros tipos de traducción, o más si cabe. $Y$ entre sus condicionantes, la audiencia es sin duda el más importante, una audiencia que impone una serie de prioridades y de restricciones. Por otro lado, en cuanto a la cuestión del intervencionismo, tengamos en cuenta que, aunque este pueda ser justificado por la voluntad de empatía del traductor con el receptor primario, el intervencionismo puede responder a la asunción de un rol de poder del traductor respecto al niño; y puede responder también a una concepción rusoniana de la infancia, según la cual es necesario proteger a los lectores infantiles de los elementos moralmente inconvenientes.
Por ello pensamos que ambas cuestiones aconsejan una mirada atenta antes de iniciar la tarea de traducción. Si lo que aparentemente parece fácil puede no serlo tanto, y lo que a primera vista parece responder a la búsqueda de empatía con el lector resulta responder a la adopción de un rol de poder, entonces quizá lo que ocurre es que la traducción de literatura para niños no es lo que a simple vista parece, y que las apariencias engañan.

Creemos que, antes de traducir este tipo de textos, es necesaria una reflexión teórica previa que nos permita abordar la tarea de traducción desde una posición no sesgada, marcada por el prescriptivismo y las ideas preconcebidas, sino desde una posición reflexiva, en la que se calibre el peso de los diferentes factores que condicionan este tipo de traducción. A este fin, presentamos una experiencia docente que realizamos con los estudiantes de la asignatura de Traducción especializada español-catalán que se imparte en el Grado en Traducción e Interpretación de la Universitat Jaume I de Castellón, y que consiste en realizar un ejercicio de reflexión teórica sobre la traducción de literatura para niños en los primeros estadios del proceso de aprendizaje que permita a los estudiantes enfrentarse a la tarea de traducción provistos de un andamiaje sólido.

\section{PRESUPUESTOS DE PARTIDA}

Al solicitar a los estudiantes que expongan cuáles son las ideas de partida que de manera intuitiva asocian a la traducción de literatura para niños, comprobamos que se reiteran las siguientes aseveraciones:

En primer lugar, los estudiantes parten de la idea de que la traducción debe adecuarse al nivel de comprensión de los lectores, y para ello el traductor debe ponerse en la piel del lector, 
hablar su lengua, conocer su registro. Y observamos en sus posturas un discurso, en general, prescriptivista, que les lleva a proponer una estrategia global de traducción manifiestamente favorable al intervencionismo.

Es ya un lugar común afirmar que en la traducción de literatura para niños se observa un alto grado de intervencionismo del traductor, justificada por una pretendida empatía del traductor con el lector potencial. Esta primera intuición ha sido clave en los estudios de traducción de literatura para niños desde los trabajos de Shavit (I98r y i986). Pero ¿cuáles son los límites del intervencionismo?, ¿hasta dónde se trata de empatía y hasta dónde de sobreprotección?

Otra idea que los estudiantes verbalizan es la del peso de la audiencia, es decir, la idea de que la toma de decisiones se ve condicionada por la marcada entidad del destinatario. El peso de la audiencia es tan relevante que hasta en la nomenclatura se incluye al destinatario, de manera que decimos 'traducción de literatura para niños' o 'traducción de literatura infantil y juvenil' (y llama la atención que entre todos los tipos y variedades de traducción, solo esta traducción, la traducción de literatura para niños, y otra más, la traducción para sordos y ciegos, incluyan al destinatario en su descriptor). Pero más allá de estas disquisiciones que nos conducirían a otro debate, y centrándonos en el tema de la audiencia en la traducción de literatura para niños, cabe preguntarse: ¿a qué audiencia nos referimos, a los niños que leen o escuchan los textos, a los adultos que son los que les proporcionan los textos, a ambos a la vez?

Otra idea que aflora es la de la sencillez, que ya hemos esbozado más arriba. Los estudiantes de traducción, si bien se han distanciado ya de los lectores infantiles, por edad e intereses, no se sienten sin embargo excesivamente alejados. Y esta cercanía les confiere una sensación de cierto dominio, una perspectiva como de hermano mayor, que les hace pensar que su función consiste en proteger al menor de todo peligro, hacerle fácil el camino como lector. $\mathrm{E}$ imbuidos por este afán de proteccionismo, se plantean como premisa inicial, de una manera intuitiva, la búsqueda de la sencillez en la traducción, y para ello la simplificación de las soluciones.

Todas estas intuiciones iniciales ponen de relieve que la traducción de literatura para niños puede ser un tipo de traducción tan condicionado y complejo como cualquier otro, por lo que creemos que se torna necesario dibujar sus contornos antes de iniciar un proyecto de traducción.

\section{REVISIÓN DE LOS CONCEPTOS TEÓRICOS}

Partimos de la lectura de tres textos de reciente aparición dedicados a la caracterización de la traducción de literatura para niños. Son las entradas de Lathey (2009: 31-34), Alvstad (2010: 22-27) y O'Sullivan (2013: 45 I-463), aparecidas en Routledge Encyclopedia of Translation Studies (2009), Handbook of Translation Studies (2010), y The Routledge Handbook of Translation Studies (20I3), respectivamente. Estos tres trabajos ofrecen, de manera precisa, un esbozo de los factores que dotan a esta rama de la traducción literaria de su singularidad. Y básicamente son los siguientes: la audiencia, la pertenencia del texto a un determinado género literario, la función de la traducción, la adaptación al contexto cultural, la manipulación ideológica, los rasgos de la oralidad y la interacción texto-imagen. Veamos cada uno de ellos sucintamente.

\section{La audiencia}

De acuerdo con las autoras, el tema de la audiencia ocupa el lugar central en la caracterización de la traducción de literatura para niños. 
El acto de traducir es siempre una actividad lingüística sometida a restricciones a causa de diferentes factores y, en el caso de la traducción de literatura infantil y juvenil, la audiencia es el factor que más claramente incide en el proceso de traducción. Tanto es así que para investigadoras como Oittinen (2000) u O'Connell (2003) es precisamente el rasgo que mejor la define.

Pero la audiencia de los textos de literatura para niños se caracteriza por su bicefalia. Es una literatura con doble destinatario: por una parte se dirige a los niños, quienes buscan entretenimiento y posiblemente también ser informados, $\mathrm{y}$ por otra parte, a los adultos, que son quienes facilitan los textos a los niños, y cuyos gustos y expectativas literarias difieren generalmente de las de los primeros. Para Oittinen (I995: Io), la adecuación del texto a una audiencia determinada condicionará las estrategias de traducción, esto es, el traductor empleará estrategias diferentes si traduce para adultos o para niños. Don Quijote, por ejemplo, se puede traducir como un 'clásico de la literatura' o como un libro para niños, y lo mismo sucede con Robinson Crusoe de Daniel Defoe (I719) o Gullivers' Travels de Jonathan Swift (I726). Ahora bien, es cierto que algunas obras de literatura para niños se dirigen solamente a los niños; sin embargo, la mayoría de las obras para niños y jóvenes son ambivalentes, pueden ser leídas por niños pero una interpretación más sofisticada del texto se reserva al adulto (O'Connell, 1999: 209-2IO). Esta doble audiencia tiene además una peculiaridad, y es su asimetría: aunque el niño es el receptor de los textos, son los adultos quienes tienen el poder $\mathrm{y}$ la influencia, $\mathrm{y}$ son ellos quienes seleccionan y compran este tipo de literatura. Y esta asimetría va más allá del producto final. En el proceso de escritura y edición es el adulto el que ocupa la posición de poder. En cada escalón del proceso son los adultos quienes actúan en nombre de los niños. Para O'Sullivan (2005), la asimetría en el proceso de comunicación es un elemento esencial en la literatura infantil y juvenil, y se manifiesta en todos los niveles del sistema literario. Hay quienes sostienen incluso que es su único rasgo específico: «the child-adult dual readership is probably the only exclusive trait of children's literature» (Alvstad, 20I0: 24). Además de la asimetría, otra peculiaridad de la traducción de literatura para niños relacionada con la audiencia es su consideración como género menor. La audiencia determina la inclusión del texto en un determinado género literario, y pertenecer a un determinado género tiene nuevamente implicaciones, como vamos a ver a continuación.

\section{Pertenencia del texto a un determinado género literario. Una literatura menor}

En los textos estudiados, las autoras insisten en el estatus marginal y el poco prestigio de la traducción en general, y de la traducción de literatura para niños en particular. Contribuye a su consideración como literatura menor el hecho de que sean textos destinados a una minoría, o que sea una literatura que se desvía de las normas literarias por el tipo de lenguaje utilizado, las estructuras sintácticas, los personajes, la carga emocional de los temas que trata y ciertas características como el contenido o el final feliz. De manera que a un menor estatus corresponde un menor reconocimiento y su estigmatización como género menor.

Para O'Connell (2006), la idea de que la traducción de literatura para niños goza de menor reconocimiento y prestigio que la traducción de la literatura para adultos se relaciona con la pertenencia del género al dominio de las mujeres. Las escritoras de textos de literatura infantil son mayoritariamente mujeres, y lo mismo ocurre con las traductoras, mayoritariamente mujeres 
también. Y pertenecer al universo femenino la estigmatiza: el sistema literario canónico tiende a infravalorarla. Este estatus de la literatura para niños como literatura menor revierte negativamente en su consideración en el ámbito profesional. No es de extrañar por tanto que los escritores de este tipo de literatura obtengan menores ingresos por su trabajo (salvadas contadas excepciones) y opten en escasas ocasiones a premios literarios prestigiosos. Escribir para niños se considera una actividad intelectualmente inferior, por lo que en ocasiones los escritores maquillan o disfrazan la actividad, como en su día hizo Perrault con la obra Contes de ma mère l'Oye (1697), en la que no se reconoció como autor:

As a member of the Académie Française, it appeared to be difficult for him to admit to absolute authorship of such simple tales, however polished their style and sophisticated irony. So radical was this departure from the learned wit and tortuous elegance of the salons and court that he distanced himself by claiming that the stories were not original creations but had been told to his son by their nurse, and that it was this son who had then recounted them in format book. (Seago, 2006: I77-178).

Shavit (1986: 35-38) equipara el estatus de la literatura para niños con el de la literatura para adultos no canonizada. La autora llega a esta afirmación tras observar el tratamiento marginal que históricamente ha recibido la literatura para niños en el ámbito universitario, con una desatención manifiesta. Para la autora, además, los cambios en la actitud hacia la literatura para niños en los programas universitarios de los años 70 y 80 del pasado siglo contribuyeron a reforzar su posición marginal al ser principalmente los departamentos de educación los que le concedían carta de naturaleza como campo de investigación. En este sentido, la literatura para niños despierta interés como instrumento educativo y no tanto como producto literario. $Y$ los premios literarios que la incluyen no hacen más que confirmar este dato; en ellos cobra más valor el pedagógico de la obra que el estrictamente literario.

Y si la consideración y el estatus de la literatura para niños son los de una literatura menor, no es casual que lo mismo ocurra con la traducción de estos textos. Para O'Connell (2006: 208-2I2), el trabajo del traductor de literatura para niños y jóvenes todavía no se reconoce de la misma manera que el trabajo del traductor de literatura para adultos, ni desde el punto de vista social, ni económico.

Shavit (1994: 4-5) describe la literatura para niños como la 'Cinderella of literary studies'. La autora (I981 y 1986) y también Weissbod (I986: 36) asocian esta baja consideración a la posición que esta ocupa en el polisistema literario, una posición periférica en contraposición con la posición central que ocupan los textos canónicos que responden a los paradigmas de la literatura para adultos seria. Hunt (I992: 2), por su parte, sugiere que esta marginalidad puede ser el reflejo de los valores implícitos de los sistemas familiares jerárquicos, que tienden a infravalorar la escritura de mujeres y los libros para niños.

¿Y ello no nos trae a la memoria también otras épocas en que escritoras (mujeres) ocultaban su identidad bajo un nombre masculino, como fue el caso de las hermanas Brontë en sus primeras obras, George Eliot (Mary Ann Evans), George Sand (Amandine Aurore Lucile Dupin), o Fernán Caballero (Cecilia Bölh de Faber) y Víctor Català (Caterina Albert)?

\section{La finalidad de la traducción}

Como acabamos de ver, la literatura para niños pertenece al mismo tiempo a dos sis- 
temas, al sistema literario y al sistema socialeducacional, es decir, no se lee solamente para la recreación y el entretenimiento sino que los adultos también utilizan la literatura para niños como herramienta para la educación y la socialización, por lo que este carácter dual afectará tanto a la escritura como a la traducción. En muchos casos, la finalidad de la traducción de literatura para niños es idéntica a la de la literatura para adultos (cuando el fin es deleitar), pero en otros casos, la finalidad es muy distinta (cuando el fin es didáctico, por ejemplo). Hoy por hoy, una de las funciones principales de un texto traducido es presumiblemente enriquecer nuestra cultura al dejarnos conocer/aprender de las otras culturas, pero en otros momentos de la historia, como en periodos posbélicos por ejemplo, la literatura era una vía de escape ante las circunstancias (Hagfors, 2003: II9).

Por todo ello, del mismo modo que no podemos estudiar una traducción sin tomar en consideración el background del autor: cuándo, dónde y por quién ha sido realizada la obra, tampoco podemos obviar su función.

\section{La interacción texto-imagen}

Otro de los rasgos más singulares de la literatura para niños es la interacción entre texto e imagen. Ello resulta especialmente relevante en los libros para edades tempranas en los que las ilustraciones se convierten en la principal fuente de información. En los libros ilustrados, los dos códigos, el lingüístico y el visual, interactúan, en general, para contar la misma historia -la imagen completa la información del texto o al revés-, o bien uno amplía la información del otro o añade otra perspectiva. En estos casos, la imagen, constituida por un conjunto de códigos (iconografía, color, planificación, fotografía, montaje-Chaume, 20I2), nos permite hablar de traducción intersemiótica, ya que dichos códi- gos hacen explícito lo que puede resultar ambiguo o lo que queda abierto en el texto escrito.

\section{Los rasgos de la oralidad}

En muchas ocasiones los textos de literatura para niños son textos escritos para ser leídos en voz alta. Rimas, repeticiones, onomatopeyas, neologismos, representaciones de los sonidos animales, etc., son parte consustancial del texto, cuando no el texto mismo. Por ello, todos estos elementos van a requerir un grado de creatividad lingüística considerable por parte del traductor y hacen necesario un conocimiento exhaustivo del registro infantil.

\section{La adaptación al contexto cultural: domesticación/extranjerización}

La audiencia, la función de la traducción, su consideración como género menor, o su permeabilidad a la manipulación, al intervencionismo, condicionan la toma de decisiones sobre qué estrategia inicial seguir: la familiarización o la extranjerización. Si se opta por la extranjerización, el resultado será una traducción que llamará la atención sobre los aspectos culturales: mostrará/enseñará qué es diferente y qué compartido entre la cultura del lector y lo que aparece en la historia. Mientras que si se opta por la domesticación, se buscarán otros fines: que los niños se identifiquen con los personajes, que comprendan mejor las historias. En cada periodo histórico se observan unas normas de traducción y los lectores tienen diferentes expectativas ante una traducción en diferentes momentos. En un periodo concreto, la norma de traducción puede ser la domesticación, en otro la extranjerización, y todo traductor, como individuo, decide si sigue las normas imperantes o si se desvía de ellas e introduce nuevas. La estrategia de traducción más apropiada dependerá del aspecto del libro que quiera ser 
transmitido a los lectores de la cultura meta, de su función en suma.

\section{La manipulación ideológica}

Como hemos visto, en la traducción de literatura para niños se hace patente, y se ve justificado, un alto grado de intervencionismo. Para Shavit (I98I y I986), la precursora de este debate, las manipulaciones a las que se someten los textos de literatura para niños se explican por la posición periférica que esta ocupa en el polisistema; ello justifica las modificaciones que realiza el traductor: «The translator of children's literature can permit himself great liberties regarding the text, as a result of the peripheral position of children's literature within the literary polysystem»(I986: II2). Manipulaciones que responden a dos principios básicos: a) que el texto sea educativo y 'good for the children' (ello explica que el texto se ajuste para que resulte apropiado y útil para los niños según los estándares morales y pedagógicos de la sociedad); b) que el texto se adecue a la habilidad lectora de los niños y a su capacidad de comprensión, es decir, que resulte comprensible y legible según las capacidades que la sociedad presupone en el niño, desde un punto de vista psicológico o cognitivo (Shavit, I98r: I72).

La autora no ofrece pautas, reglas de traducción, no dice cómo se ha de traducir, sino que describe normas de traducción, a partir del estudio de las traducciones de Los viajes de Gulliver y Robinson Crusoe (Shavit, I986: II5). Así, enumera cinco normas:

I. La afiliación del texto a modelos existentes en la literatura meta: cuando Robinson Crusoe, por ejemplo, se tradujo a otras lenguas se convirtió en un cuento para niños porque la sátira no existía como modelo en los textos para niños en esas culturas.
2. La integridad de los modelos textuales primarios y secundarios: es posible omitir esquemas del texto e incluso partes y escenas que no concuerden con la moral dominante de la cultura meta; ello incluye lo que los adultos creen que los niños no pueden comprender, como el tema de la muerte, por ejemplo.

3. El grado de complejidad y sofisticación del texto: se pueden obviar los elementos irónicos, por ejemplo.

4. La adecuación del texto a propósitos didácticos e ideológicos: es lo que Klingberg (r986) define como purification.

5. La adaptación a las nomas estilísticas de una determinada cultura: como se observa en las traducciones al hebreo en las que se eleva el registro con el fin de ampliar el vocabulario de los niños.

Todos estos condicionantes (la visión de la infancia, la pertenencia de este tipo de traducción a un determinado género, la función de la traducción, la estrategia global de traducción adoptada, la manipulación ideológica o la interacción texto-imagen, a las que se suman las características textuales y discursivas particulares del texto) dotan a la traducción de literatura infantil de su singularidad y determinan las decisiones de traducción.

Antes de concluir este apartado, y a modo de conclusión, podríamos representar gráficamente en el diagrama r los elementos vistos hasta aquí.

Cada proyecto de traducción estará condicionado por los factores que entran en juego en la traducción de literatura para niños y que, de manera sumativa, conforman un todo de continentes y contenidos. Un esquema que nos recuerda el juego de cubos apilables en el que cada cubo contiene otro, y este, otro más, y así sucesivamente; y en el que todos tienen un peso 
Audiencia

Género textual

Función de la traducción

Adaptación al contexto cultural

Manipulación ideológica

Interacción texto-imagen

Características textuales y discursivas

Diagrama I.

Proyecto de traducción $\rightarrow$

específico en la consecución del resultado: en nuestro caso, en las decisiones de traducción.

\section{REVISIÓN DE LOS TÓPICOS}

Una vez visibilizados los diferentes condicionantes de la traducción de literatura para niños, es el momento de retomar las ideas de partida que de manera intuitiva habíamos esbozado al inicio de este trabajo. En primer lugar, se hace necesario revisar el concepto de intervencionismo. Hemos convenido que la audiencia es el elemento nuclear sobre cuya órbita gravitan los demás factores que intervienen en este tipo de traducción, por lo que resulta necesario seguir profundizando en el conocimiento de los lectores potenciales, de la infancia en primer término. Muchos textos traducidos para niños tienden a infravalorar a los lectores infantiles al sobreprotegerlos frente a la entrada de ele- mentos culturales 'no familiares' o moralmente inconvenientes. Son ideas procedentes de los postulados de Rousseau, que han calado hondo y que siguen muy arraigadas en las mentes contemporáneas. Pero hemos de considerar también que esta sobreprotección puede conducir a la adaptación como norma y, con ello, dejar poca cabida a la extranjerización, al acceso a otras culturas.

O'Sullivan (2013: 453) advierte de las implicaciones de estos desequilibrios y propone una solución que pasa por el calibrado de fuerzas:

Translating children's literature is therefore a balancing act between adapting foreign elements to the child reader's level of comprehension, and to what is deemed appropriate, and preserving the differences that constitute a translated foreign text's potential for enrichment of the target culture. 
La toma de decisiones sobre el grado de intervención se convierte en un ejercicio de responsabilidad en el que se torna necesario un conocimiento exhaustivo del receptor pero también del texto y su contexto, un estudio minucioso de las posibilidades expresivas en lengua meta y un no menos profundo conocimiento de la función de la traducción. De este modo, la traducción para niños se convierte en un tipo de traducción tan complejo o más si cabe que la traducción para adultos, y es erróneo pensar que la búsqueda de la sencillez, que puede ser el objetivo, sin duda, quiera decir que la operación de traducción sea una operación sencilla.

Si comparamos la traducción de literatura para niños con la traducción de literatura para adultos, probablemente en un primer momento nos fijaremos en la extensión de los textos y en sus características formales, por lo que no es descabellado que asociemos el concepto de traducción de literatura para niños al de simplicidad, y de ahí que todas las decisiones que tomemos estén condicionadas por esta premisa inicial. Hunt (I991: I6r) ofrece un listado de las características (o más exactamente de los estereotipos) del lenguaje y la estructura de la literatura para niños. Y enumera los siguientes: la sencillez de las estructuras sintácticas, la limitada variedad léxica y complejidad gramatical, el registro simple, el empleo de frases estándar, léxico simple, palabras de la vida cotidiana, repeticiones, y frases y textos breves. En lo que al contenido se refiere, el autor sostiene que se observa la ausencia o poca presencia de detalles históricos, detalles técnicos o de especialidad, la preferencia por los temas mágicos-fantasíasimplicidad-aventura; temas como la infancia, la amistad, las relaciones familiares, el proceso de maduración; y se evitan temas como la violencia, la muerte, el sexo, el horror, la guerra, las normas sociales controvertidas, el alcohol o los insultos. Rudvin y Orlati (2006: 162) añaden la preferencia por los diálogos y los acontecimientos en lugar de la descripción, la introspección o la disquisición; la preferencia por lo concreto en lugar de lo abstracto, lo indeterminado o lo ambiguo; o la preferencia por el avance rápido de la trama, por el movimiento y la acción más que por el estatismo, la inactividad o la reflexión.

$\mathrm{Y}$, ciertamente, los textos de literatura para niños pueden ser en general de menor extensión y requerir recursos lingüísticos de menor complejidad y un menor dominio formal de la lengua, así mismo la improvisación puede tener mayor cabida; pero ello no significa necesariamente que traducirlos resulte una actividad sencilla por norma. Por otro lado, de acuerdo con Hunt (I99r: 16r), aunque común, es erróneo pensar que la calidad literaria asociada a altos niveles de complejidad en la forma y el contenido es incompatible con la literatura dirigida a los niños.

La idea de que traducir para niños es una actividad fácil se sustenta sobre la base de que la literatura para niños es un género menor. Y la consecuencia que se deriva de ello es la siguiente: como es considerada una actividad fácil, en la que no se precisan unas habilidades específicas por parte de los traductores, no se solicita ningún tipo de especialización, como sí ocurre por el contrario con otras ramas de la traducción, como la traducción jurídica o la traducción audiovisual. $Y$ en esto los planes de estudios de los diferentes grados y antiguas licenciaturas en Traducción han tenido su parte de responsabilidad al no contemplarla como materia curricular y no formar a traductores especializados en esta rama, a pesar de tratarse de una parcela de enorme actividad traductora. También desde el punto de vista investigador es un área de estudios marginal y desatendida. 
O'Connell (2006) añade, por otro lado, que no es solamente el mundo académico el responsable del bajo estatus de la traducción de la literatura para niños sino también las editoriales. Las casas editoriales deciden qué obras se van a traducir y, por lo general, la selección de los textos responde a criterios ideológicos y económicos más que a criterios literarios.

Para Fernández López (2006: 52), sin embargo, "Contrary to the simplistic view that holds the literary study of children's literature as necessarily of less complexity than corresponding studies of adult literature, translation studies reveal yet again the richness of the field and the need for multidisciplinary research». Un campo de estudio de amplias posibilidades, rico, que reclama una investigación multidisciplinar. Citando a Chester (1989: 5), la autora sostiene que en los estudios de literatura para niños se entrecruzan diversas esferas, la esfera literaria, la artística y la histórica, y son estudios que interactúan con otras disciplinas como la crítica literaria, la educación, la sociología, la psicología, y son una parte importante de la historia social. En su opinión, los estudios de traducción de literatura infantil han puesto de manifiesto el desacierto de la etiqueta de sencillez en esta parcela investigadora, lo que hacemos extensivo a su práctica. Del mismo modo, cabe replantear la idea de que traducir para niños es una actividad de menor rango por pertenecer al universo femenino. Compartimos con O'Connell (2006) la necesidad de buscar las razones de esta marginalidad en los diversos estratos del entramado literario. Como sostiene Hunt (20Ir: 47), recogiendo una cita de Thacker (2000), "Children's literature is marginalized by being excluded from critical and theoretical discourses to which it could contribute vitally».

\section{PROPUESTA DIDÁCTICA}

Los temas tratados hasta aquí ponen de manifiesto que la traducción de literatura para niños se revela como una actividad condicionada que reclama una mirada atenta a sus peculiaridades y a los tópicos que la acompañan antes de iniciar un proyecto de traducción.

Presentamos a continuación una experiencia docente llevada a cabo con los estudiantes de la asignatura de Traducción especializada español-catalán, que se imparte en el cuarto curso del Grado en Traducción e Interpretación de la Universitat Jaume I, en la que planteamos la necesidad de reflexionar sobre las características de la traducción de literatura para niños antes de enfrentarnos a su traducción. Está integrada por las siguientes actividades: r) En primer lugar, traducimos un texto breve, sin ningún soporte teórico, lo que nos da pie a abrir un debate en el que exponemos nuestras ideas preconcebidas sobre la traducción de literatura para niños; 2) en segundo lugar, leemos tres textos teóricos básicos, en los que se reflexiona sobre sus características definitorias; 3 ) y en tercer lugar, valoramos las traducciones resultantes de la actividad I, a partir del sustrato teórico y crítico con el que contamos, y replanteamos los tópicos que más frecuentemente se asocian a la traducción de literatura para niños. Veamos someramente el desarrollo de cada una de las actividades.

En la actividad I, planteamos un sencillo ejercicio: se trata de traducir al catalán (variedad valenciana) un fragmento perteneciente al libro de Vicente Muñoz Puelles (1998) Óscar y el león de Correos, publicado en Anaya, en la colección Sopa de Libros, y dirigido a niños de 6 años en adelante. La actividad consiste en traducir únicamente las dos frases señaladas en negrita del texto que ofrecemos a continuación, con estas mínimas consignas de traducción: 
—la lengua de llegada (catalán -variedad valenciana)

- la edad de los destinatarios (la misma que la de los destinatarios del texto origen: a partir de 6 años)

- y la editorial y colección en que se publicaría la traducción (Anaya, Colección Sopa de Llibres)

El león de Correos nunca se escondía. Pasaba casi todo el día al sol, con la cabeza colgando del edificio de Correos como si estuviera disecada. En realidad era un buzón. ¡Pero qué buzón! Tenía la mirada feroz y la boca abierta, llena de afilados dientes. [...]

[Óscar] sabía que no estaba vivo, pero eso era lo más terrible, porque a veces la expresión le cambiaba. ¿Y cómo podía cambiarle la expresión si no estaba vivo?

A su hermana Eva tampoco le asustaba. Cuando papá o mamá la tomaban en brazos, dejaba caer el sobre en la boca del león y se reía como si fuera lo más divertido del mundo.

Tampoco Óscar había tenido miedo del león de Correos al principio, antes de cumplir los seis años.

Lo aupaban, soltaba la carta y el león hacía un gesto como si la tragase. A veces hasta se oía un pequeño ruido, como cuando estalla una burbuja.

$$
-i \text { Gulp! }
$$

Los papás no se enteraban de nada. Era algo entre el león de Correos y él.

(Óscar y el león de Correos, pág. 25-26)

I La traducción, publicada en la misma editorial de manera simultánea a la aparición del original, es la siguiente:

El lleó de Correus no s'amagava mai. Passava quasi tot el dia al sol, amb el cap penjant de l'edifici de Correus com si estiguera dissecat. En realitat era una bústia. Però quina bústia! Tenia la mirada ferotge i la boca oberta, plena de dents afilades. [...]

[Óscar] sabia que no era viu i això era més terrible, perquè a vegades l'expressió li canviava. I com podia canviar-li l'expressió si no era viu?
Y valgan estos ejemplos como muestra de algunas de las soluciones ofrecidas:

Lo aupaban, soltaba la carta y el león hacía un gesto como si la tragase. A veces hasta se oía un pequeño ruido, como cuando estalla una burbuja.

El pujaven al cavallet, llançava la carta i el lleó feia un gest com si se l'estigués empassant. De vegades, fins $\mathrm{i}$ tot, se sentia un xicotet soroll, com quan una bombolla es trenca.

(Literalmente: Lo subían a caballito, tiraba la carta y el león hacía un gesto como si se la estuviese tragando. A veces, incluso, se oía un pequeño ruido, como cuando una burbuja se rompe).

El feien upa, amollava la carta i el lleó feia un gest com si se l'engolira. De vegades, fins i tot, se sentia un sorollet com quan peta una bombolla.

(Literalmente: Lo aupaban, soltaba la carta y el león hacía un gesto como si la engullera. A veces, incluso, se oía un ruidito, como cuando revienta una burbuja).

L'agafaven en braços, llançava la carta i el lleó feia un gest com si se l'empassara. De vegades, fins i tot, es sentia un suau soroll com si estallara una bombolla.

A la seua germana Eva tampoc no l'espantava. Quan el pare o la mare l'agafaven als braços, deixava anar el sobre dins la boca del lleó i reia com si fóra la cosa més divertida del món.

A Óscar tampoc no li havia fet por el lleó de Correus al principi, abans de fer els sis anys.

El feien upa, llançava la carta i el lleó feia un gest com si l'engolira. De vegades, fins i tot, se sentia un soroll xicotet, com quan esclata una bombolla.

-Gloc!

Els pares no s'assabentaven de res. Era un assumpte entre el lleó de Correus i ell.

Óscar i el lleó de Correus (Traducción de Maria Àngels Giménez Campos), pág. 24-26. 


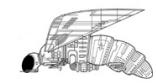

134
(Literalmente: Lo cogían en brazos, tiraba la carta y el león hacía un gesto como si se la tragara. A veces, incluso, se oía un suave ruido como si estallara una burbuja).

L'alçaven, soltava la carta i el lleó feia un gest com si se l'engolira. De vegades, fins i tot, s'escoltava un xicotet soroll com si esclatara una bombolla.

(Literalmente: Lo levantaban, soltaba la carta y el león hacía un gesto como si la engullera. A veces, incluso, se escuchaba un pequeñito ruido como si explotara una burbuja).

Diseccionando algunas de las unidades que aparecen en estas opciones de traducción, vemos que, aun siendo un fragmento tan breve, se observan distintas soluciones de traducción como muestran los siguientes ejemplos:

'Lo aupaban', que resulta:

- 'el pujaven al cavallet' (lo subían a caballito)',

- 'el feien upa' (lo aupaban),

- 'l'alçaven' (lo levantaban/lo subían),

- 'l'agafaven en braços' (lo cogían en brazos);

'un pequeño ruido':

- 'un suau soroll' (un suave ruido),

- 'un xicotet soroll' (un pequeño ruido),

—'un sorollet' (un ruidito);

'estalla una burbuja':

- 'una bombolla es trenca' (una burbuja se rompe),

- 'peta una bombolla' (revienta una burbuja),

- 'estalla una bombolla' (estalla una burbuja),

- 'esclata una bombolla' (explota una burbuja).

Como son soluciones que responden a nuestras primeras intuiciones sobre cómo proceder ante un texto de literatura para niños, les pedimos que las observen y que opinen sobre su idoneidad. Y ello nos da pie a abrir un debate

2 Ofrecemos una traducción literal entre paréntesis. sobre cuáles son nuestras primeras intuiciones respecto a la traducción de literatura para niños.

Ya hemos consignado brevemente en el apartado I de este artículo cuáles son estas primeras intuiciones; las recordamos nuevamente:

-Intervencionismo ¿dónde están los límites? 'Aupar' no quiere decir lo mismo que 'pujar al cavallet' (que literalmente sería 'subir a caballito'; 'peta una bombolla' pertenece a un registro distinto a 'estalla una burbuja').

- La audiencia: ¿a qué audiencia nos referimos? Poniendo 'suau soroll' ¿pensamos en los niños, o en los adultos?

-Sencillez: ¿es sencillo llegar a la solución 'peta una bombolla' o 'esclata una bombolla' cuando en castellano la traducción literal nos daría una solución que sería correcta en este contexto: 'estalla una burbuja' para 'estalla una bombolla'?

¿Son estas premisas, la audiencia, la sencillez y la opción del intervencionismo, las que explican la validez de la traducción de 'pujar al cavallet' (subir a caballito) para 'lo aupaban' en este contexto, a pesar de que contiene un No mismo sentido? ('Pujar al cavallet', aunque es muy usual en el lenguaje infantil, no quiere decir lo mismo que 'lo aupaban'; 'el pujaven al cavallet' tendría un correlato en la forma en castellano 'lo subían a caballito', cuyo sentido no es exactamente el mismo que el de 'lo aupaban').

Para responder a estos interrogantes planteamos la actividad 2, que consiste en proponer a los estudiantes la lectura de los tres textos teóricos referenciados más arriba y dedicados a la revisión teórica de los principales conceptos teóricos esenciales para abordar la especificidad del género. Recordémoslos, eran los de Lathey (2009: 31-34), Alvstad (2010: 22-27) y O'Sullivan (2013: 45I-463).

Tras la lectura, proponemos una puesta en común de las ideas resultantes, de manera que 
obtengamos un primer esbozo de los factores que dotan a la traducción de literatura para niños de su singularidad: la audiencia, la pertenencia del texto a un determinado género literario, la función de la traducción, la adaptación al contexto cultural, la manipulación ideológica, los rasgos de la oralidad o la interacción textoimagen. Y que no reproducimos aquí puesto que ya han sido resumidos en el apartado mencionado.

Concluidas la lectura de los textos y la exposición de los conceptos teóricos obtenidos, les proponemos la actividad 3 , que consiste en valorar las soluciones de traducción propuestas por los estudiantes en la actividad I, provistos ahora de este soporte teórico.

La actividad se desarrolla del siguiente modo: solicitamos a los estudiantes que examinen las traducciones resultantes de la actividad I y que las valoren. Para ello deben ordenar las soluciones del I al 4, desde la más satisfactoria desde su punto de vista, que sería la número I, hasta la menos satisfactoria, la número 4 , y que expliquen las razones de su decisión. Se ponen en común las soluciones, y este es el orden resultante propuesto de manera mayoritaria:

\section{Lo aupaban, soltaba la carta y el león hacía un} gesto como si la tragase. A veces hasta se oía un pequeño ruido, como cuando estalla una burbuja.

I El feien upa, amollava la carta i el lleó feia un gest com si se l'engolira. De vegades, fins i tot, se sentia un sorollet com quan peta una bombolla.

(Literalmente: Lo aupaban, soltaba la carta y el león hacía un gesto como si la engullera. A veces, incluso, se oía un ruidito, como cuando revienta una burbuja).

2 L'alçaven, soltava la carta i el lleó feia un gest com si se l'engolira. De vegades, fins i tot, s'escoltava un xicotet soroll com si esclatara una bombolla.

(Literalmente: Lo levantaban, soltaba la carta y el león hacía un gesto como si la engullera. A veces, incluso, se escuchaba un pequeñito ruido como si explotara una burbuja).

3 El pujaven al cavallet, llançava la carta i el lleó feia un gest com si se l'estigués empassant. De vegades, fins i tot, se sentia un xicotet soroll, com quan una bombolla es trenca.

(Literalmente: Lo subían a caballito, tiraba la carta y el león hacía un gesto como si se la estuviese tragando. A veces, incluso, se oía un pequeñito ruido, como cuando una burbuja se rompe).

4 L'agafaven en braços, llançava la carta i el lleó feia un gest com si se l'empassara. De vegades, fins i tot, es sentia un suau soroll com si estallara una bombolla.

(Literalmente: Lo cogían en brazos, tiraba la carta y el león hacía un gesto como si se la tragara. A veces, incluso, se oía un suave ruido como si estallara una burbuja).

Y se observa que las soluciones mejor valoradas son las traducciones que, en su opinión, más se adecuan a la manera de hablar de los niños de la edad indicada (a partir de 6 años). Era preferida la forma 'fer upa' (para la forma del texto original 'aupar'), o 'alçar' (levantar) que otras como 'agafar en braços' (coger en brazos), y lo mismo sucedía con 'peta una bombolla' (explota una burbuja) o 'esclata una bombolla' (revienta una burbuja), que eran mejor valoradas como propuesta de traducción para el original 'estalla una burbuja' que la traducción literal 'estalla una bombolla'. Incluso son bien valoradas soluciones que contienen No mismos sentidos, como es el caso de la forma 'el pujaven al cavallet', que ya hemos comentado, y que se juzga como aceptable en este texto.

Las traducciones mejor valoradas son las que 
contienen lo que los estudiantes consideran que los niños van a recibir mejor: un discurso más próximo al del niño, un discurso que reconozcan y en el que se reconozcan: 'el feien upa', 'se sentía un sorollet', 'peta una bombolla'... Vemos pues que se ha otorgado mejor puntuación a las traducciones que contienen más elementos del registro infantil. Estos resultados nos permiten matizar los tópicos apuntados, como era la idea de la sencillez y con ella la de intervencionismo como garante de esa sencillez. Las soluciones mejor valoradas en este ejercicio eran las que respondían a un grado de elaboración mayor por lo que a la consecución del registro se refiere.

Así, pues, pensamos que el andamiaje teórico del que los estudiantes disponen ahora les permite valorar con mayor solidez sus opciones y las de sus compañeros, así como matizar las intuiciones y los tópicos iniciales. Esto consiente establecer los límites de la manipulación al calibrar el peso de los distintos factores que entran en juego en la toma de decisiones. Ahora pueden justificar sus elecciones, y por tanto las decisiones de traducción, en función de los factores que caracterizan este tipo de traducción. Y ciertamente la audiencia ocupa el espacio mayor en las decisiones de traducción, lo que se plasma en la valoración que obtienen las soluciones más acordes con el registro infantil. Pero no podemos afirmar que las soluciones mejor valoradas sean las más sencillas, ni podemos afirmar que la búsqueda de soluciones pertenecientes a este registro sea una actividad sencilla per se. La consecución de un registro lingüístico cercano al lector, con el que este se identifique, generalmente exige al traductor un ejercicio de documentación no exento de complejidad.

La docencia de la traducción entre dos lenguas cercanas como son el español y el catalán, un tipo de traducción también en una posición marginal y a la que a priori se le asigna el calificativo de traducción sencilla, es un ejemplo de que es precisamente en la sencillez donde en infinidad de ocasiones se presentan las dificultades de traducción. Cuando traducimos entre dos lenguas como el español y el catalán, traducimos 'confiados' y sin el estado de alerta que reclama la traducción entre otras parejas de lenguas no marcadas por el rasgo de proximidad formal (García de Toro, 2009), y ello nos conduce a automatismos que en muchos casos son causantes de errores, como en el ejemplo siguiente: traducir el verbo catalán 'sentir' al español de manera automática por 'sentir' en frases como 'Ho sents?' (¿Lo sientes?), cuando quizá a lo que se refiera esta palabra en la frase/el texto pueda ser a 'oír' ('¿Lo oyes?’). Un supuesto similar se hace extensivo a la traducción de literatura para niños: la idea de simplicidad planea en las mentes de los traductores, de manera que es comprensible que, llevados por ella, el esfuerzo que realicemos sea menor que ante un texto literario para adultos en el que se presupone mayor complejidad en la forma y el contenido. La sencillez es pues en muchas ocasiones un espejismo, más el reflejo de lo que queremos ver, que de lo que realmente es.

Pensamos, para concluir, que los primeros contactos con la reflexión teórica en los momentos iniciales del proceso de aprendizaje son un prerrequisito necesario antes de iniciar un proyecto de traducción: nos pueden ayudar a encarar nuestra traducción con mayor solidez, a situar el objeto de estudio desde una óptica menos prescriptiva y a adoptar un punto de vista crítico, tan necesario ante un tipo de traducción tan rodeado de tópicos.

RECIBIDO EN DICIEMBRE DE 2013

ACEPTADO EN FEBRERO DE 2OI4 VERSIÓN FINAL DE DICIEMBRE DE 2013 


\section{REFERENCIAS BIBLIOGRÁFICAS}

Alvstad, C. (2010). «Children's literature and translation», en Gambier, Y. y L. van Doorslaer (eds), Handbook of Translation Studies, Ámsterdam y Filadelfia: John Benjamins, pp. 22-27.

Chaume, F. (2012). Audiovisual Translation: Dubbing, Manchester: St. Jerome.

Chester, T. R. (1989). Children's Books Research: A Practical Guide to Techniques and Sources, South Woodchester: Thimble.

Fernández López, M. (2006). «Translation Studies in Contemporary Children's Literature: A Comparison of Intercultural Ideological Factors», en Lathey, G. (ed), The Translation of Children's Literature. A Reader, Clevedon: Multilingual Matters, pp. $4 \mathrm{I}^{-} 53$.

Hagfors, I. (2003). "The Translation of CultureBound Elements into Finnish in the Post War Period», Meta, 48, pp. II5-I27.

Hunt, P. (1990). Children's Literature: The Development of Criticism, Londres y Nueva York: Routledge.

Hunt, P. (1991). Criticism, Theory, and Children's Literature, Oxford: Basil Blackwell.

Hunt, P. (20II). "Children's Literature», en Nel, Philip y Lissa, Paul (20II). Keywords for Children's Literature, Nueva York: New York Univesity, p. 42-47.

Hunt, P. (2009). «Children's literatura and childhood», en Kehily M.J. (ed), An introduction to chilodhood studies, Berkshire: Open University Press, McGraw-Hill, pp. 50-69.

Klingberg, G. (1986). Children's Fiction in the Hands of the Translators, Malmö: Liber/Gleerup.

Lathey, G. (2009). «Children's Literature», en Baker, M. y G. Saldanha (eds), Routledge Encyclopedia of Translation Studies, Londres y Nueva York: Routledge, pp. 31-34.

Muñoz Puelles, V. (1998). Óscar y el león de Correos, Madrid: Anaya, Col. Sopa de Libros.

Muñoz Puelles, V. (I998). Óscar y el león de Correos, traducción de Maria Àngels Giménez Campos, Madrid: Anaya, Col. Sopa de Llibres.
O'Connell, E. (2003). Minority Language Dubbing for Children, Berna: Peter Lang.

O’Connell, E. (I999/2006). «Translating for Children", en Lathey, G. (ed), The Translation of Children's Literature, A Reader, Clevedon: Multilingual Matters, pp. 15-24.

Oittinen, R. (1995). «The verbal and the visual: On the carnivalism and dialogics of translating for children», Compar(a)ison, 2, pp. 49-65.

Oittinen, R. (2000). Translating for Children, NuevaYork: Garland Publishing..

O'Sullivan, E. (2005). Comparative Children's Literature, Londres: Routledge.

O'Sullivan, E. (2013). "Children's Literature and translation studies», en Millán, C. y F. Bartrina (eds), The Routledge Handbook of Translation Studies, Londres y Nueva York: Routledge, pp. $45 \mathrm{I}-463$.

Rudvin, M. y Orlati, F. (2006). «Dual Readership and Hidden Subtext in Children's Literature: The Case of Salman Rushdie's Haroun and the Sea of Stories», en Van Coillie, J. y W. P. Verschueren (eds.), Children's Literature in Translation: Challenges and Strategies, Manchester: St. Jerome Publishing, pp. I57-184.

Seago, K. (I995/2006). «Nursery Politics: Sleepenig Beauty ot teh Acculturation of a Tale», en Lathey, G. (ed), The Translation of Children's Literature, A Reader, Clevedon: Multilingual Matters, pp. I75-I89.

Shavit, Z. (I98I). «Translation of Children's Literature as a Function of Its Position in the Literary Polysystem», Poetics Today, 2 (4), pp. I7I-I79.

Shavit, Z. (I986). Poetics of Children's Literature, Athens, Georgia: University of Georgia Press.

Shavit, Z. (1994). "Beyond the Restrictive Frameworks of the Past: Semiotics of Children's Literature - A New Perspective for the Study of the Field», en Ewers, H-H., Lehnert, G. y E. O'Sullivan (eds), Kinderliteratur im Interkulturellen Prozess. Stuttgart y Weimar: Verlag J. B. Metzler, pp. 3-15. 